\title{
Inserção do tema sustentabilidade no curso de Ciências Contábeis à luz da teoria Institucional: FEA/USP
}

\author{
Karina Rocha Henriques Gehlen \\ https://orcid.org/0000-0002-9202-9665
}

Luciano Gomes dos Reis

https://orcid.org/0000-0001-6388-2790

Kelli Juliane Favato

https://orcid.org/0000-0001-8360-8318

\section{Resumo}

Objetivo: Compreender o processo de institucionalização do tema sustentabilidade no curso de Ciências Contábeis da Faculdade de Economia, Administração e Ciências Contábeis da Universidade de São Paulo (FEA/USP).

Método: Estudo de caso exploratório com entrevistas semiestruturadas com 8 docentes que estão envolvidos com o tema e/ou presenciaram a sua inserção no curso. Empregou-se a análise de conteúdo, na qual foram estabelecidas 6 categorias. A triangulação dos dados foi estabelecida utilizando as respostas dos entrevistados e os Projetos Políticos Pedagógicos (PPP) referentes aos anos 2000, 2006, 2009, 2013 e 2016. Resultados: Demonstram que o tema sustentabilidade está semi-institucionalizado em transição para o institucionalizado. A natureza do conceito de sustentabilidade adotado pelo curso possui características de manutenção do status quo e reformista. Concluiu-se que a disciplina que aborda sustentabilidade tem atributos mais holísticos e interdisciplinares do que o curso de contabilidade como um todo.

Contribuições: A contribuição prática deste estudo é servir de base para que outras instituições possam inserir o tema sustentabilidade em seus projetos pedagógicos. Quanto à contribuição teórica, o estudo mostra a aplicabilidade da teoria Institucional de modo empírico, além do nível organizacional empresarial, adentrando no ambiente educacional.

Palavras-chave: Teoria institucional; Sustentabilidade; Ensino superior em Ciências Contábeis. 


\section{Introdução}

As provocações acarretadas pela obra Primavera Silenciosa (Carson, 1962) foram um dos marcos para as discussões ambientais. Na sequência, agendas e conferências motivaram discussões que envolvem política governamental, negócios corporativos e a sociedade quanto aos desafios da sustentabilidade (Adams, Heijltjes, Jack, Marjoribanks \& Powell, 2011). A necessidade de um mundo mais sustentável ficou ainda mais evidente diante a crise financeira global de 2008. A partir de então, a sustentabilidade foi estabelecida como uma área que carece de atenção de líderes empresariais, governos, universidades e organizações não governamentais (Annan-Diab \& Molinari, 2017).

Na última década, a Organização das Nações Unidas (ONU) colocou a educação no centro de sua estratégia para promover o desenvolvimento sustentável, apoiando iniciativas como os Princípios de Educação para a Gestão Responsável (PRME), que está comprometida em liderar mudanças transformacionais em direção a uma liderança mais social e ambientalmente responsável (Assumpção \& Monzoni Neto, 2020). Annan-Diab e Molinari (2017) e Figueiró e Raufflet (2015) corroboram que há um impulso para incorporar a sustentabilidade nos projetos pedagógicos. Além do mais, os sistemas de educação têm sido um reflexo das aspirações e desafios postos na sociedade (Assumpção \& Monzoni Neto, 2020). Acrescenta-se que as universidades têm influência significativa sobre uma proporção dos futuros líderes do mundo, abrangendo a responsabilidade em formar líderes e agentes de mudança no desenvolvimento de uma sociedade mais sustentável (Assumpção \& Monzoni Neto, 2020, Adams et al., 2011; Jacobi, Raufflet, \& Arruda, 2011; Adams, 2018).

A discussão ganhou urgência nos últimos anos, e práticas sustentáveis e éticas são uma preocupação crescente para profissionais da contabilidade (Wyness \& Dalton, 2018). Nota-se que é um desafio para as Instituições de Ensino Superior (IES) tornarem-se facilitadoras e responsáveis por argumentos que contribuirão para a construção de uma sociedade sustentável (Jacobi, 2003). O que se percebe é uma adesão, por parte das universidades, em inserir o tema sustentabilidade em diversas áreas do conhecimento, incluindo cursos da área de negócios, cujo impacto dessa área no mundo corporativo é indiscutível (Jacobi, Raufflet \& Arruda, 2011; Gonçalves-Dias, Herrera \& Cruz, 2013).

No entanto, apesar de uma série de iniciativas e de um número crescente de universidades buscando engajamento com o desenvolvimento sustentável, a maioria das IES continuam sendo tradicionais ao empregar paradigmas reducionistas e mecanicistas no ensino (Lozano, Lukman, Lozano, Huisingh \& Lambrechts, 2013). Disto, destacam-se as críticas de Chulián (2011) de que as escolas de contabilidade ainda desenvolvem aptidão apenas para habilidade técnica da profissão, ou seja, gestão econômica e financeira, o que pode ser ainda mais agravante quando excluem a possibilidade de debater um cenário sustentável. Wyness e Dalton (2018) inferem que, apesar de a inclusão da sustentabilidade nos programas de graduação em contabilidade ser um tema discutido nas duas últimas décadas, existe uma disparidade considerável entre a extensão em que a sustentabilidade foi incorporada nas escolas de contabilidade em todo o mundo.

Nesse contexto, para que se possa proteger o interesse público, é necessária uma mudança no quadro do ensino em contabilidade (Gray \& Collison, 2002), utilizando-se dos formatos atuais e inserindo competências críticas, transdisciplinares e comunicativas para auxiliar na transformação da disciplina (Saravanamuthu, 2015). Os preceitos teoria Institucional (Dimaggio \& Powell, 2005) favorecem acompanhar tais mudanças, uma vez que as organizações são levadas a incorporarem determinadas práticas e procedimentos que são definidos por conceitos racionalizados (Meyer \& Rowan, 1977). E, segundo Berger e Luckmann (2011), a existência humana é decorrente de um contexto que envolve ordem, direção e estabilidade.

Portanto, ao relacionar-se a relevância do contador à tomada de decisão no meio corporativo e a incipiência de discussões nas IES na formação líderes com uma visão crítica do modelo negócios para uma perspectiva sustentável, emerge a seguinte questão de pesquisa: Como ocorre o processo de institucionalização do tema sustentabilidade na FEA USP? Para responder à questão de pesquisa, o presente estudo tem por objetivo, por meio de um estudo de caso único, compreender o processo de institucionalização do tema sustentabilidade no curso de Ciências Contábeis da FEA/USP. 
Justifica-se essa problemática, diante da incipiência de estudos que observem o processo de institucionalização do ensino de contabilidade com a temática de sustentabilidade. Ademais, a problemática proporciona à academia aumentar as discussões quanto à necessidade de inserção da sustentabilidade nos níveis de graduação, bem como a importância da formação do profissional consciente e crítica às relações sociais, econômicas e ambientais para a formação do contador.

A contribuição prática deste estudo é servir de base para que outras instituições possam inserir o tema sustentabilidade em seus projetos pedagógicos. E a contribuição teórica demonstra a aplicabilidade da teoria Institucional de modo empírico, além do nível organizacional empresarial, adentrando no ambiente educacional. Assim, uma investigação sobre como a sustentabilidade vem se institucionalizando nos cursos de Ciências Contábeis, possui relevância no campo de ensino superior. Tratando-se de uma disciplina formadora de profissionais que irão atuar com gestores, sendo as informações contábeis, de cunho econômico, social e ambiental responsáveis pelo auxílio na tomada de decisão, tão logo, importantes para a sociedade como um todo.

\section{Referencial Teórico}

\subsection{Inserção da sustentabilidade no ensino superior e no ensino de contabilidade}

Existem acordos e declarações internacionais relacionadas à sustentabilidade no ensino superior (Wright, 2004), como a Declaração de Talloires (DT), Halifax Declaration (Canadá, 1991), Kyoto Declaration (Japão, 1993), Swansea Declaration (País de Gales, 1993), Copernicus Charter (Barcelona, 1994), Declaration of Thessaloniki (Grécia, 1997) e Lüneburg Declaration (Alemanha, 2001). Em 2005, a Assembleia Geral das Nações Unidas estabeleceu a Década da Educação para o Desenvolvimento Sustentável (EDS), momento em que foi ressaltado que a educação é um elemento indispensável para que se possa atingir o desenvolvimento sustentável (UNESCO, 2005). Após a iniciativa do EDS, o Pacto Global da ONU definiu a iniciativa para as escolas de negócios, que é o PRME. Criado em 2007, o PRME foi lançado na Cúpula de Líderes do Pacto Global da ONU, em um encontro com a presença de mais de 1.000 líderes empresariais, da sociedade civil e do Governo. O objetivo básico do PRME é desenvolver capacidades para que os alunos sejam geradores de valor sustentável para uma economia global mais inclusiva por meio do ensino, pesquisa e extensão (Parkes, Buono \& Howaidy, 2017).

Ao assumir professores como agentes educadores das próximas gerações, bem como da atual geração de líderes empresariais, as escolas de negócios estão em uma posição única para influenciar mentalidades e ações de algumas das maiores e mais poderosas organizações do planeta (Parkes et al., 2017). Logo, o compromisso básico com o aprimoramento da educação em gestão responsável pode ser caracterizado como uma jornada indispensável. Gonçalves-Dias, Herrera e Cruz (2013) concluem que as mudanças do ensino superior vão além de novos conteúdos dos currículos, devendo passar por uma reformulação de modelos de ensino-aprendizagem e novas competências na formação docente. No entanto, quanto à necessidade de reformulações no âmbito empírico, nota-se uma possível lacuna da academia em propor a reformulação, pois o estudo de Figueiró e Raufflet (2015) realizou um levantamento da literatura na área de gestão, e poucos estudos situam, na filosofia e no design mais amplo da educação, como essa mudança poderia e seria alcançada pelo desenho do curso ou paradigmas educacionais explícitos.

Hahn e Reimsbach (2014) levantam uma preocupação quanto à mera integração superficial da sustentabilidade no currículo escolar dos estudantes, pois, embora o contador não atue diretamente nas práticas de sustentabilidade, mas, sim, como um comunicador destas práticas, acredita-se que a sustentabilidade deve integrar as disciplinas-chaves de gestão, como Contabilidade e Finanças, pois a inclusão de disciplinas eletivas não atinge todos os alunos (Rasche et al., 2013; Hahn \& Reimsbach, 2011). 
Corroborando, nesse sentido, as informações/a preocupação acima, os resultados de Silva Junior, Vasconcelos, Silva e Campos (2019) inferem que a noção de sustentabilidade não é compartilhada pelos respondentes, cuja amostra contou com 1.882 respondentes de graduação e pós-graduação em administração e contabilidade no Brasil. As conclusões estabelecem uma prevalência da dimensão econômica em detrimento das demais dimensões, ancorada na lógica oportunista e utilitarista que permeia a formação do contador. Logo, existe a necessidade de reflexão acerca da formação educacional desses discentes, sobretudo, pela necessidade de se repensar o modelo de educação vigente rumo a uma lógica sustentável.

Diante do exposto, percebe-se que o campo ainda está em construção com relação ao ensino de sustentabilidade ao discente de contabilidade. Para Gray e Collison (2002), há uma série de problemas relacionados à profissão contábil, dentre eles o de que a contabilidade é intimamente ligada às estruturas da modernidade, vendo as questões ambientais como marginais e que a problemática pode ter sido desencadeada pelo fato de os profissionais da contabilidade não receberem "educação filosófica", mas, sim, o que os autores denominam como "treinamento" voltado à técnica. Eles argumentam que a sustentabilidade deve constituir um módulo central em todos os programas de contabilidade no interesse dos alunos, da profissão contábil e da sociedade em geral, de modo a progredir de um 'convidado bem-vindo' em contabilidade (Gray, 2013) para um sujeito residente permanente (Wyness \& Dalton, 2015).

\subsection{Teoria Institucional}

Dimaggio e Powell (1983) apontam uma tendência isomórfica das organizações, ou seja, a tendência das organizações se assemelharem. A mudança isomórfica institucional ocorre devido a três mecanismos, conforme Tabela 1.

Tabela 1

Mecanismos de isomorfismo instituciona

\begin{tabular}{|c|c|c|}
\hline Isomorfismo Coercitivo & Isomorfismo Mimético & Isomorfismo Normativo \\
\hline $\begin{array}{l}\text { Resultado de pressões formais } \\
\text { e informais que são exercidas } \\
\text { sobre as organizações } \\
\text { por outras organizações. } \\
\text { Decorrente da dependência } \\
\text { entre elas ou das expectativas } \\
\text { culturais da sociedade sobre as } \\
\text { organizações. }\end{array}$ & $\begin{array}{l}\text { Derivado de situações } \\
\text { complexas, nas quais as } \\
\text { soluções não são nítidas. } \\
\text { Assim, tomam outras } \\
\text { organizações como } \\
\text { modelos e fonte de práticas } \\
\text { organizacionais. }\end{array}$ & $\begin{array}{l}\text { Originado principalmente da profissionalização com } \\
\text { o intuito de definir as condições, métodos e controle } \\
\text { de seu trabalho. } \\
\text { Decorre da educação formal por meio de } \\
\text { legitimação baseada na cognição produzida na } \\
\text { especialização universitária e do crescimento } \\
\text { ou constituição de redes de relacionamento } \\
\text { profissional que são responsáveis por difundir } \\
\text { novos modelos. }\end{array}$ \\
\hline
\end{tabular}

Fonte: elaborado com base em Dimaggio e Powell (1983).

\subsubsection{Processos de Institucionalização}

Esta subseção trata especificamente dos processos de institucionalização, tomando como base o estudo de Tolbert e Zucker (1999), que utilizam as definições de Schutz sobre ações tornadas habituais e tipificação. A primeira se caracteriza pelos comportamentos desenvolvidos de forma empírica e adotados por atores, com o objetivo de resolver problemas rotineiros. Já a tipificação envolve a reciprocidade de definições ou significados compartilhados, ligados aos comportamentos habituais. O poder coercitivo das instituições ocorre sobre o indivíduo, no qual as tipificações possuem uma realidade própria e externa a este. De acordo com Zucker (1977), a exterioridade está relacionada com a continuidade histórica das tipificações e a transmissão aos novos membros. "Toda instituição tem um corpo de conhecimento transmitido como receita, isto é, conhecimento que fornece regras de conduta institucionalmente adequadas" (Berger; Luckmann, 2011, p. 90). 
Tolbert e Zucker (1999) classificam que as ações, quando adquirem a qualidade de exterioridade, são chamadas de sedimentação. Nessa acepção, com a ênfase da exterioridade em um conjunto de comportamentos, a transmissão aumenta o grau de institucionalização dos comportamentos, que por sua vez interfere nas futuras transmissões (Tolbert \& Zucker, 1999). Com isso, o conjunto de processos que são sequenciais (habitualização, objetificação e sedimentação) sugere a variação nos níveis de institucionalização em relação ao grau de profundidade de ligação no sistema social, em estabilidade, e poder de determinação de comportamentos. O processo se inicia com a inovação, que surge por meio de mudanças tecnológicas, força do mercado ou legislação. A partir disso, inicia-se o processo de habitualização, que, ao ter um monitoramento interorganizacional e teorização, passa para a próxima etapa que é a objetificação. Após a análise dos impactos positivos, do nível de resistência do grupo e da defesa do grupo de interesse, é possível verificar se o processo chegou ao nível de sedimentação.

Logo, a habitualização é uma espécie de resposta aos problemas organizacionais, ou uma formalização de arranjos em políticas e procedimentos, que podem ocorrer em uma ou mais organizações que enfrentem problemas semelhantes, sendo assim, tais processos resultam em um estágio de préinstitucionalização. De acordo com Dimaggio e Powell (2005, p. 84), nos campos em que há alto grau de incerteza, os ingressantes, "que poderiam servir como fontes de inovação e variação, procurarão superar a obrigatoriedade de inovação imitando práticas estabelecidas dentro do campo". Nesse contexto, no estágio de pré-institucionalização, organizações similares podem adotar uma estrutura de acordo com as circunstâncias correlatas em que possam estar inseridas.

Nesse sentido, o movimento que levaria a um status mais permanente é o processo de objetificação (Tolbert \& Zucker, 1999; Zucker, 1977). A objetificação pode ter como elemento-chave o chamado champion, ou o indivíduo ou grupo de indivíduos que lutam ou defendem uma causa, promovendo mudanças estruturais nas organizações. Para que haja um sucesso com relação à ação dos champions, é preciso que estes identifiquem o problema organizacional e depois desenvolvam teorias que servirão para diagnosticar as fontes de insatisfação ou fracasso, apresentando, assim, uma solução ao problema (Tolber \& Zucker, 1999, p. 209). Portanto, as estruturas que se objetificaram e, foram disseminadas de forma ampla, estão no estágio de semi-institucionalização, em que a difusão deixa de ter caráter imitativo, passando a ter uma base normativa, refletindo a teorização implícita ou explícita das estruturas, e uma taxa de sobrevivência maior do que na fase pré-institucional, embora ainda não perdurem.

A sedimentação caracteriza-se tanto pela propagação de suas estruturas por todo o grupo de atores teorizados como adotantes adequados quanto pela perpetuação de estruturas por um período consideravelmente longo de tempo (Tolber \& Zucker, 1999, p. 209). Dessa forma, a compreensão do processo de sedimentação é a identificação dos fatores, no que concerne à abrangência do processo de difusão e à conservação em longo prazo da estrutura. A Figura 1 mostra o resumo das características dos processos de institucionalização.

\begin{tabular}{|c|c|c|}
\hline $\begin{array}{l}\text { HABITUALIZAÇÃO } \\
\text { - Ligada à questão da inovação } \\
\text { organizacional, sendo que a } \\
\text { criação de novas estruturas ocorre } \\
\text { por meio de atividades } \\
\text { independentes. } \\
\text { - Espécie de resposta aos } \\
\text { problemas organizacionais tais } \\
\text { processos resultam em um estágio } \\
\text { de pré institucionalização. }\end{array}$ & $\begin{array}{l}\text { OBJETIFICAÇÃo } \\
\text { - Tem como elemento chave o } \\
\text { indivíduo ou grupo de indivíduos } \\
\text { que promovem mudanças } \\
\text { estruturais nas organizações. } \\
\text { - Ligado a estruturas disseminadas } \\
\text { de forma ampla, estágio de semi- } \\
\text { institucionalização, em que a } \\
\text { difusão deixa de ter caráter } \\
\text { imitativo para ter base normativa. }\end{array}$ & $\begin{array}{l}\text { SEDIMENTAÇÃO } \\
\text { - Ligada à institucionalização } \\
\text { total, fundamentada na } \\
\text { história da estrutura, } \\
\text { sobrevivendo assim por } \\
\text { várias gerações. }\end{array}$ \\
\hline
\end{tabular}

Figura 1. Processos de Institucionalização

Fonte: elaborado com base em Tolbert \& Zucker, 1999; Zucker, 1977. 
A institucionalização total da estrutura dependerá de alguns fatores: baixa resistência de grupos de oposição, apoio e promoção continuado dos grupos defensores e relação positiva com os resultados alcançados (conforme Tabela 2).

Tabela 2

Estágios de institucionalização e dimensões comparativas

\begin{tabular}{llll}
\hline Dimensão & Estágio Pré-Istitucional & Estágio Semi-Institucional & $\begin{array}{l}\text { Estágio de total } \\
\text { Institucionalização }\end{array}$ \\
\hline Processos & Habitualização & Objetificação & Sedimentação \\
\hline Características dos adotantes & Homogêneos & Heterogêneos & Heterogêneos \\
\hline Ímpeto para difusão & Imitação & Imitativo/normativo & Normativa \\
\hline Atividade de teorização & Nenhuma & Alta & Baixa \\
\hline Variância na implementação & Alta & Moderada & Baixa \\
\hline Taxa de fracasso estrutural & Alta & Moderada & Baixa \\
\hline Fonte: Tolbert e Zucker (1999, p. 201). & & &
\end{tabular}

Com isso, o trabalho apresentado tem uma grande valia para testes empíricos, o que está diretamente ligado ao propósito desta pesquisa. É por meio dos processos apresentados que se irá buscar identificar em qual estágio de institucionalização estará inserido o caso analisado.

\section{Procedimentos Metodológicos}

Esta pesquisa é caracterizada como qualitativa com estudo de caso único (YIN, 2010). Para a escolha do objeto de estudo, foram consideradas, em primeiro lugar, instituições públicas, pois não possuem restrições em divulgar documentos necessários para a análise. O segundo critério foi que a IES possua cursos de Ciências Contábeis com disciplinas que abordem sustentabilidade em seus projetos pedagógicos e, como terceiro critério, que tenham núcleo de estudos voltados para sustentabilidade dentro desse curso.

Assim, com essas características foram encontradas duas instituições de ensino, a FEA/USP e uma outra IES. Após contato com ambas as instituições, apenas a primeira autorizou a realização da pesquisa.

A instituição escolhida para a condução desta pesquisa foi a FEA/USP. Justifica-se esta escolha considerando que USP está no $1^{\circ}$ lugar do ranking da Webometrics que classifica universidades da América Latina. O corpo docente da FEA/USP conta com professores formadores de opinião em contabilidade e sustentabilidade no Brasil, por exemplo, a primeira tese em contabilidade ambiental foi orientada pelo professor Dr. Eliseu Martins. Os docentes estão alinhados a importantes movimentos, como a participação do professor Dr. Nelson Carvalho no International Integrated Reporting Council (IIRC) e o professor Dr. Eduardo Flores como board no IIRC, bem como a participação do professor Dr. José Roberto Kassai no Comitê Brasileiro de Relato Integrado (CBARI). A FEA/USP é signatária do PRME em busca de uma educação executiva responsável, alinhado à Unesco.

A coleta de dados foi realizada com entrevista semi-estruturada, legislação e normas educacionais brasileiras e os PPPs disponibilizados pela instituição referentes aos anos 2000, 2006, 2009, 2013 e 2016 em vigência atualmente. Esse processo é necessário para que se possa identificar em qual momento ocorreu a inserção de disciplinas ligadas à sustentabilidade, podendo assim fazer um parâmetro com a literatura e o contexto histórico dessa ocorrência.

Quanto às entrevistas, entende-se que questões abertas, mesmo que direcionadas por um roteiro, alcançam as suposições implícitas dos selecionados (Flick, 2004, p. 106). Em um primeiro contato, ficou estabelecido que seriam cinco entrevistados que estavam envolvidos com o tema ou presenciaram sua inserção no curso. Durante as entrevistas, mais três entrevistados foram apontados para contribuírem com a pesquisa, totalizando 8 participantes. 
A análise dos dados foi feita por meio da análise de conteúdo, na qual etapas foram feitas, conforme o trabalho de Moraes (1999), que envolve: preparação (pré-leitura de matérias), unitarização (divisão do tema em unidades de análise), categorização, descrição e interpretação. As categorias e subcategorias (Tabela 3) foram elaboradas de acordo com o referencial teórico do trabalho, ou seja, foram preestabelecidas. A partir desta construção teórica, as categorias foram definidas de duas formas. Com relação ao processo de institucionalização, foram retiradas do trabalho de Beltrame (2015), enquanto novas categorias emergiram do referencial teórico sobre sustentabilidade, educação para sustentabilidade e contabilidade.

Neste trabalho, foram analisados os projetos político pedagógicos do curso de Ciências Contábeis da instituição selecionada a partir do ano 2000. Isso se deve ao fato de a teoria Institucional demandar um estudo que abranja vários anos para que se possa verificar quando ocorreu o momento da inserção oficial da disciplina de Sustentabilidade nos referidos cursos. Outros documentos analisados envolvem legislação (Lei n. ${ }^{\circ}$ 9.597/1999) sobre Educação Ambiental (EA), Resolução da FEA/USP n. ${ }^{\circ}$ 4097, de julho de 1994 (versão consolidada com alteração), Diretrizes Curriculares Nacionais para o Curso de Graduação em Ciências Contábeis, normas para cadastramento em certificação internacional, além do site institucional e o acesso às disciplinas ofertadas por meio da plataforma Moodle. A triangulação foi feita utilizando as respostas dos entrevistados, cujo conteúdo das questões foi feito a partir da categorização preestabelecida, além dos documentos coletados na instituição. A Tabela 3 apresenta uma síntese do procedimento metodológico da pesquisa, demonstrando a ligação entre os objetivos deste trabalho, as categorias de análise, as questões elaboradas e os autores utilizados na análise dos dados. Foi verificado se a sustentabilidade aplicada ao curso busca uma manutenção do status quo (entendido nesse trabalho como mudanças incrementais da atual organização social), reforma ou transformação radical social, com base no trabalho de Hopwood, Mellor e O'Brien (2005). Essa classificação foi conduzida em conjunto com as divisões dos processos de institucionalização (habitualização, objetificação e sedimentação). 
Tabela 3

Síntese do procedimento metodológico

\begin{tabular}{|c|c|c|c|c|}
\hline $\begin{array}{l}\text { Roteiro de Análise } \\
\text { (seção 4) }\end{array}$ & Categorias & Subcategorias & Roteiro de Questões & Referências \\
\hline $\begin{array}{l}\text { Verificar como } \\
\text { ocorreu a } \\
\text { inserção do tema } \\
\text { sustentabilidade no } \\
\text { curso de Ciências } \\
\text { Contábeis do caso } \\
\text { estudado. }\end{array}$ & & & $\begin{array}{l}\text { Como surgiu a ideia de inserção } \\
\text { do tema sustentabilidade no } \\
\text { curso de CC? Quais os principais } \\
\text { atores envolvidos? Teve algum tipo } \\
\text { de resistência? }\end{array}$ & $\begin{array}{l}\text { PPPs }(2000,2006 \\
2009,2013,2016)\end{array}$ \\
\hline $\begin{array}{l}\text { Identificar qual o } \\
\text { tipo de isomorfismo } \\
\text { se apresentou no } \\
\text { caso estudado. }\end{array}$ & Isomorfismo & $\begin{array}{l}\text { Mimético } \\
\text { Coercitivo } \\
\text { Normativo }\end{array}$ & $\begin{array}{l}\text { Para a inserção do tema } \\
\text { sustentabilidade no curso de CC } \\
\text { ocorreu algum tipo de pressão } \\
\text { interna ou externa? Houve inspiração } \\
\text { de alguma outra instituição? }\end{array}$ & $\begin{array}{l}\text { Dimaggio } \\
\text { e Powell } \\
(1983,2005) .\end{array}$ \\
\hline \multirow{3}{*}{$\begin{array}{l}\text { Analisar qual } \\
\text { o nível de } \\
\text { institucionalização } \\
\text { do tema } \\
\text { sustentabilidade } \\
\text { no curso. }\end{array}$} & Habitualização & $\begin{array}{l}\text { Inovação; } \\
\text { Estrutura; Políticas; } \\
\text { procedimentos }\end{array}$ & \multirow{3}{*}{$\begin{array}{l}\text { Há algum tipo de consenso sobre } \\
\text { o valor dessa nova estrutura com a } \\
\text { USP e com outros cursos da FEA? Há } \\
\text { apoio institucional? } \\
\text { A presença da sustentabilidade no } \\
\text { curso de CC tem trazido resultados } \\
\text { positivos? Internos e externos? } \\
\text { Os professores têm dificuldade } \\
\text { de inserir sustentabilidade em } \\
\text { suas disciplinas? Há algum tipo de } \\
\text { incentivo para isso? } \\
\text { Como é resistência hoje sobre o } \\
\text { ensino de sustentabilidade no curso? }\end{array}$} & \multirow{3}{*}{$\begin{array}{l}\text { Tobert e Zucker } \\
\text { (1999); Lei } \\
\text { 9.9795/99; } \\
\text { DCN Curso de } \\
\text { Graduação } \\
\text { em Ciências } \\
\text { Contábeis (2004). }\end{array}$} \\
\hline & Objetificação & $\begin{array}{l}\text { Consenso social; } \\
\text { Difusão da estrutura; } \\
\text { Presença de } \\
\text { champions }\end{array}$ & & \\
\hline & Sedimentação & $\begin{array}{l}\text { Resultados positivos; } \\
\text { Continuidade da } \\
\text { estrutura; Baixa } \\
\text { resistência }\end{array}$ & & \\
\hline \multirow{2}{*}{$\begin{array}{l}\text { Apresentar a } \\
\text { natureza do } \\
\text { conceito de } \\
\text { sustentabilidade } \\
\text { adotado pelo curso. }\end{array}$} & Sustentabilidade & Natureza do conceito & $\begin{array}{l}\text { Qual é o conceito de } \\
\text { Sustentabilidade adotado pelo curso } \\
\text { de CC da FEA/USP? Há utilização de } \\
\text { mais de um conceito? } \\
\text { De acordo com o conceito adotado } \\
\text { espera-se algum tipo de mudança } \\
\text { social? Que tipo? Incremental, } \\
\text { reformista, radical? }\end{array}$ & \multirow{2}{*}{$\begin{array}{l}\text { Gray Collison } \\
\text { (2002); Hopwood, } \\
\text { Mellor e O'Brien } \\
\text { (2005); Chulián } \\
\text { (2011); Rasche et } \\
\text { al. (2013); Hahn } \\
\text { e Reimsbach } \\
\text { (2014); Costa e } \\
\text { Loureiro (2013); } \\
\text { Jocobi (2003); } \\
\text { Gonçalves e } \\
\text { Martendal } \\
\text { et al. (2013); }\end{array}$} \\
\hline & $\begin{array}{l}\text { Educação para a } \\
\text { sustentabilidade } \\
\text { na Contabilidade }\end{array}$ & $\begin{array}{l}\text { Pensamento } \\
\text { holístico } \\
\text { Iterdisciplinaridade } \\
\text { Resultados para } \\
\text { a sociedade }\end{array}$ & $\begin{array}{l}\text { Há diálogo com outras áreas do } \\
\text { conhecimento na disciplina de } \\
\text { Sustentabilidade? } \\
\text { A ideia central da disciplina é } \\
\text { apresentar conteúdo de forma } \\
\text { ampla ou com foco na contabilidade? }\end{array}$ & \\
\hline
\end{tabular}




\section{Análise dos Dados}

\subsection{Origem e inserção do tema sustentabilidade no curso}

De 2000 a 2008, não há menção sobre EDS ou EA nos projetos pedagógicos do curso. No ano de 2009, o projeto pedagógico inseriu a disciplina optativa Balanço Social, que dentro de seu conteúdo possui o Balanço Ambiental. Em 2013, manteve a mesma disciplina.

Em 2016, houve a inserção de mais duas disciplinas optativas que abrangem questões ambientais no âmbito das Ciências Contábeis, que são: Relato Integrado e Sustentabilidade e Estudos Complementares (cada semestre um novo tema é abordado), por exemplo, no segundo semestre de 2016 o tema era "Os 17 Objetivos do Desenvolvimento Sustentável e as Escolas de Negócio”. O programa da disciplina de Relato Integrado e Sustentabilidade ainda possui vídeo-palestras de presidentes de grandes empresas engajados no tema da sustentabilidade, palestras e workshop, programas educacionais, livros e a revista Ideia Sustentável. Há ainda sugestões sobre os mais diversos temas relacionados ao meio ambiente, consumo, política e economia.

A primeira fase da pesquisa foi descobrir quais os motivos que levaram ao interesse de inserir dentro do curso de Ciências Contábeis da USP o tema sustentabilidade. Nesse sentido, os principais fomentadores desse processo foram os entrevistados $\mathrm{A}$ e $\mathrm{B}$, no qual o primeiro começou a ministrar disciplinas no assunto dentro de Estudos Complementares, o segundo foi um dos integrantes do IIRC,que foi o órgão internacional precursor do Relato Integrado.

O EntB aponta duas origens para ter trazido o tema para dentro da contabilidade. A primeira foi quando se deparou com o conceito de triple botton line, no qual não deveria privilegiar somente o botton line, que é o lucro líquido, mas que pessoas e planeta também eram importantes. O segundo momento foi a participação do EntB no IIRC, em que, segundo ele, houve um questionamento do Príncipe de Gales sobre o papel do contador, em uma realidade que já havia sido tomada por ambientalistas, engenheiros, advogados e economistas.

EntB. Isso aterrissou aqui porque, porque eu acabei fazendo parte do conselho (IIRC), [...] aí eu trouxe essa disciplina e eu consegui encantar o EntA, [...] construiu uma disciplina que ele conduz, eu conduzo em parceria, mas ele está em todas as aulas presente, criando sensibilidade e essa disciplina tem sido um sucesso [...].

O entrevistado G corrobora com essa mesma afirmação, conforme fragmento abaixo:

EntG. A disciplina como o EntA dá, como o EntB também traz, ela atrai muitos alunos de outros cursos, assim como a contabilidade atrai muitos profissionais de outras áreas [...] basicamente administradores financeiros interessados na contabilidade, [...], você não teria estudantes de outras áreas interessados no conceito de contabilidade ambiental, contabilidade sustentável.

EntE. Então a gente passou a oferecer essa disciplina com alguma frequência, foi mais ou menos nessa época que o EntA começou a investir nesse tema, começou a se especializar [...].

Nota-se que, em primeiro lugar, houve a identificação dos champions que, de acordo com Tolbert e Zucker (1999), são os responsáveis por trazer as inovações e defender as ideias junto a outros integrantes do grupo. Nesse caso, os champions são EntA e EntB. Outro ponto observado é que a inserção do tema partiu de um contexto de mudanças sociais e não necessariamente de uma coerção por meio de normas ou leis. 


\subsection{Identificação do isomorfismo}

Primeiramente, com relação ao isomorfismo no Brasil, não há uma norma específica que obrigue os cursos de Ciências Contábeis a inserirem em seus currículos, uma disciplina que aborde o tema sustentabilidade. Embora, a Lei n. ${ }^{\circ}$ 9.795/1999 regulamente que a Educação Ambiental deva estar em todos os níveis do processo educativo, isso ainda não se apresentou de forma clara na resolução do CNE, que institui as Diretrizes Curriculares Nacionais para o Curso de Graduação em Ciências Contábeis. Nesse sentido, as instituições de ensino podem ou não inserir EA ou EDS em sua matriz curricular, o que demonstra também uma clara dissonância entre a legislação e a resolução direcionada diretamente ao curso. Com isso, o isomorfismo coercitivo, que segundo Dimaggio e Powell (1983) são caracterizados como pressões formais exercidas sobre as organizações, podendo vir de ordens governamentais, não se aplica ao presente estudo.

Quanto ao isomorfismo mimético, os entrevistados foram questionados sobre a inspiração em outras instituições de ensino:

EntA. Essa disciplina se não me engano é a primeira do mundo. Na verdade, a gente se inspirou na necessidade do mercado mesmo.

EntB. Nossa inspiração vem disso que eu te falei, tanto do triple bottom line, quanto da minha participação no IIRC. EntE. Que eu tenho registro eu não lembro de algo assim. Eu lembro de a gente ter discutido tema, desenvolver pesquisa, e aí foi uma coisa natural.

EntG. Eu não tenho conhecimento sobre esse processo, mas com certeza a USP foi referência no Brasil, sobre as experiências das outras universidades.

Nesse contexto, o isomorfismo normativo, que tem relação com a educação formal baseada na cognição produzida na especialização universitária e a constituição de redes de relacionamento profissional, é responsável por difundir novos modelos. Conforme Dimaggio e Powell (1983), um dos mecanismos que estimula o isomorfismo é a seleção de pessoal, a qual pode ocorrer pelo recrutamento de pessoal, com alto desempenho em grupos restritos de instituições, como executivos de alto padrão que atuam nos departamentos financeiros e/ou jurídicos. O EntB e EntG discorrem sobre esse processo de sucessão de cargos:

EntB. [...] então eu tenho que recrutar e reter os talentos que aquele modelo de gestão vai ajudar a produzir resultados, e isso aqui foi responsável pelo sucesso de passado.

EntG. O perfil do aluno de contabilidade da FEA ele é diferente, por exemplo, de algumas outras universidades que formam alunos que vão trabalhar em pequenos escritórios de contabilidade, aqui pelo estereótipo nosso a maioria dos alunos são cooptados pelas grandes empresas.

Com relação a esse ambiente seleto de empresas, o EntD aponta que faz parte do universo de convívio do EntB, que é um dos responsáveis pela inserção do tema no curso de CC.

EntD. [...] E EntB ele tem uma capacidade de liderança muito grande então ele trouxe muita gente pra esse negócio de Relato Integrado, por exemplo, [...] então ele sentiu isso no nível de mercado que ele está.

Com esses pontos destacados, é possível identificar o tipo de isomorfismo, o normativo, ligado à especialização profissional e principalmente à sucessão de cargos dentro de uma empresa. Ainda de acordo com os trechos selecionados, os entrevistados associam o conhecimento sobre sustentabilidade e a habilidade de um contador de saber produzir relatórios que abordem tais questões a cargos de alto nível em instituições com alto valor agregado. 
Isso demonstra que o aluno que tem acesso a tais conhecimentos, tem maior chance de se destacar no mercado de trabalho. No entanto, esse tipo de comportamento educacional pode gerar uma desigualdade no processo de contratação por parte das empresas. Isso porque nem todas as instituições de ensino superior abordam o tema em seus cursos de ciências contábeis, fazendo com que os alunos não tenham as mesmas oportunidades de ocupar cargos altos, em grandes corporações, por uma deficiência na formação. Destaca-se um ponto da teoria de Dimaggio e Powell (2005, p. 129): "os campos organizacionais que compreendem uma força de trabalho profissionalmente treinada serão guiados principalmente por uma competição de status".

\subsection{Habitualização, objetificação e sedimentação}

Com relação ao primeiro momento do processo de institucionalização, a habitualização, envolvendo inovação, estrutura e políticas e procedimentos, não se apresenta no caso estudado. De acordo com Tolbert e Zucker, a habitualização ou pré-institucionalização, está ligada às incertezas que permeiam uma atividade econômica e obrigam as empresas a buscarem estratégias competitivas. Nesse caso, é uma instituição educacional, a qual viu nas próprias mudanças que ocorrem socialmente, tanto de cunho ambiental quanto de mercado, a necessidade de inserir uma disciplina que abordasse $\mathrm{o}$ assunto.

Dentro deste nível não há alto grau de incerteza, o que não foi identificado em nenhuma fala dos entrevistados. Têm-se questões que irão apresentar o nível de institucionalização a partir da objetificação e da sedimentação. Um dos principais pontos para essa análise é a presença de resistência de um grupo ou de pessoas que se opõem à nova proposta. Com relação a isso, segue um resumo dos respondentes:

EntA. Não aqui não teve, [...]. Não teve dificuldade nenhuma.

EntB. Nenhum, até porque não é só sobre sustentabilidade, sempre que um professor propõe a criação de uma disciplina, isso sempre é visto com muitos bons olhos.

EntC. Ao contrário, as pessoas acabam vendo como uma alternativa pra você fazer novos estudos.

A fala dos entrevistados demonstra que não há resistência para o ensino da sustentabilidade no curso. $\mathrm{O}$ fato de mais de uma disciplina ter sido desenvolvida ao longo do tempo também retrata essa ausência de resistência por parte de outros docentes. Nesse sentido, não há grupos opositores que, segundo Tolbert e Zucker, caracterizam o nível de sedimentação, assim como apoio e promoção dos grupos defensores e relação positiva com os resultados alcançados.

Com relação ao apoio institucional, é possível destacar que os entrevistados possuem visões diferentes, o que é atribuído ao fato de que uma instituição de ensino tem certa autonomia com relação aos arranjos hierárquicos institucionais. Sobre os resultados positivos de inserção do tema no curso, os entrevistados focaram no fato dos alunos que podem trabalhar com isso em empresas, mas alguns também citaram a produção científica que sai da universidade.

Com relação à estrutura, foi questionado aos entrevistados sobre as relações com outros departamentos, ou outras áreas do conhecimento.

EntA. Nosso núcleo de pesquisa [...] tem umas 50 pessoas [...]. Ele é multidisciplinar.

EntB. É bastante próxima, nós temos alunos de biologia, de comunicação, de economia [...].

EntC. Muito pouco, você não tem, infelizmente é uma coisa que a gente reclama, tem uma questão física que normalmente a gente coloca dentro da universidade, uma questão interinstitucional [...].

EntD. A nossa estrutura é muito verticalizada em departamentos, os departamentos não conversam muito

[...] é essa coisa cada um meio por si. 
Como visto, as opiniões são bem divergentes sobre a relação interinstitucional assim como com relação às outras áreas do conhecimento. O que se percebe é que os envolvidos com o tema sustentabilidade, mesmo que de forma indireta, admitem que é necessário que haja envolvimento com as outras áreas do conhecimento, enquanto os que não são envolvidos diretamente possuem uma visão mais cética a respeito dessa troca de conhecimento.

Nesse sentido, é possível identificar em qual fase de institucionalização o tema sustentabilidade se encontra no curso. A Tabela 4, retirada da teoria de Tobert e Zucker (1999), demonstra os estágios de institucionalização e as dimensões comparativas, sendo que nessa nova versão estão destacados os estágios nos quais se encontra o curso de Ciências Contábeis da FEA/USP.

Tabela 4

Identificação dos estágios de institucionalização e dimensões comparativas

\begin{tabular}{llll}
\hline Dimensão & Estágio Pré-Institucional & Estágio Semi-Institucional & $\begin{array}{l}\text { Estágio de Total } \\
\text { Institucionalização }\end{array}$ \\
\hline Processos & Habitualização & Objetificação & Sedimentação \\
\hline Características dos adotantes & Homogêneos & Heterogêneos & Heterogêneos \\
\hline Ímpeto para difusão & Imitação & Imitativo/normativo & Normativa \\
\hline Atividade de teorização & Nenhuma & Alta & Baixa \\
\hline Variância na implementação & Alta & Moderada & Baixa \\
\hline Taxa de fracasso estrutural & Alta & Moderada & Baixa \\
\hline
\end{tabular}

Fonte: Tobert e Zucker (1999, p. 201).

Conforme o quadro apresentado, o tema sustentabilidade se encontra nos estágios grifados, ou seja, entre o estágio semi-institucionalizado (objetificação) e o institucionalizado (sedimentação). A característica dos adotantes é heterogênea, mesmo os que não utilizam o tema como centro de pesquisa. Um exemplo disso é que o EntC e EntE já ministraram a disciplina de Balanço Social e já foram convidados para palestrar na disciplina de Relato Integrado, assim como o EntD.

Pelo que foi observado durante a pesquisa, a taxa de fracasso estrutural é baixa devido à autonomia que cada departamento tem em inserir disciplinas ou temas relacionados ao conteúdo de contabilidade sem qualquer tipo de impedimento.

A dimensão de variância de implementação não se aplica ao caso estudado, já que ela está relacionada ao número de organizações que começam uma determinada estrutura e cada uma varia a forma como isso é feito. No caso da USP, não há como identificar essa variância, pois, para saber sobre essa dimensão seria necessária uma pesquisa mais abrangente sobre as demais instituições de ensino, o que acaba por não se aplicar a um estudo de caso único.

Nesse contexto, a teoria é aplicada até certo ponto, dado que as características de uma organização acadêmica são diferentes em diversos níveis de uma organização empresarial, no que concerne busca de lucro, permanecia de mercado, níveis estratégicos e competição. 


\subsection{Educação para Sustentabilidade na Contabilidade}

Após analisar em qual nível de institucionalização o tema sustentabilidade se apresenta no curso, é possível adentrar sobre como é a visão dos atores envolvidos acerca do ensino de sustentabilidade.

Gray e Collison (2002) descrevem que os professores podem não ser capazes ou não querer aprender/ensinar sobre o assunto. Isso foi considerado pelos entrevistados ao serem questionados sobre barreiras para o ensino da sustentabilidade:

EntD. Depende do professor, eu acho que vai muito da visão quase que pessoal, se a pessoa acredita nisso, ou acha que isso existe, ou acha que isso é importante.

EntG. Então a grande dificuldade pra se ensinar essas coisas não necessariamente é a existência de um grupo opositor. Mas é a existência de professores capacitados dentro de uma coisa tão multidisciplinar como é o conceito.

Outros entrevistados trouxeram ao assunto a questão da dificuldade de inserir o tema de forma transversal com outras disciplinas. De acordo com Rasche et al. (2013), a sustentabilidade deve integrar as disciplinas-chaves de gestão, como Finanças. Chullián (2011) aponta que o papel do professor-pesquisador tem uma contribuição positiva sobre a mudança de valores da futura geração de contadores. Todavia, como observado, essa não é uma tarefa fácil, primeiro os professores teriam que, de alguma forma, incorporar os conceitos de sustentabilidade dentro de sua área de conhecimento e pesquisa, mesmo dentro das disciplinas-chaves e avançadas do curso como Contabilidade Fiscal, Societária, Custos e Gerencial.

A superficialidade pode estar no fato de não se aprofundar sobre o assunto, principalmente devido à dificuldade dos próprios professores conseguirem dialogar com as questões ambientais e sociais dentro de suas disciplinas e, por outro lado, segundo Rasche et al. (2013), a inclusão de disciplinas eletivas não atingem todos os alunos.

Nesse momento, se faz necessária uma discussão envolvendo a Lei n. ${ }^{\circ}$ 9.795/1999, que aponta a EA como uma prática educativa integrada, que não deve ser implantada como uma disciplina específica no currículo de ensino. De forma suplementar, deve estar nos currículos de formação dos professores, em todos os níveis e em todas as disciplinas, sendo ainda que os professores deveriam receber formação complementar.

O trabalho de Gray e Collison (2002) também aborda questões envolvendo os discentes, segundo eles, os alunos fazem a opção pela faculdade de contabilidade por razões de satisfação, sucesso antecipado, interesse e gosto. Já os alunos que optam por estudar tais disciplinas tendem a relacionar esses conhecimentos às opiniões pessoais, e não ao futuro da carreira.

No entanto, um dos motivos que levou à inserção do tema sustentabilidade no curso foi a necessidade do mercado de absorver contadores com conhecimento sobre o assunto, já que os contadores são responsáveis pela divulgação das práticas empresariais. De acordo com informações dadas pelo coordenador do curso, que corroboram com documentos disponibilizados, 513 alunos se matricularam em disciplinas optativas ofertadas que envolviam Sustentabilidade, Balanço Social, Meio Ambiente, EDS, sendo 227 alunos em disciplinas de Relato Integrado e Sustentabilidade desde 2013. É válido ressaltar que as diretrizes do Relato Integrado iniciaram as discussões, em 2010, com o IIRC e a sua implementação ocorreu em 2013. Logo, a instituição demonstra estar alinhada às práticas do mercado. 


\subsection{Conceito de Sustentabilidade}

Para apresentar qual a natureza de EA ou EDS presente no curso analisado, a partir da análise das disciplinas e da fala dos entrevistados, buscou-se identificar o conceito abraçado pelo curso e onde ele se colocaria dentro do mapeamento de Hoopwood et al. (2005), que divide as abordagens entre manutenção do status quo, reformista ou de transformação radical da sociedade.

Ainda que o conteúdo das disciplinas traga, em sua maioria, sugestão de texto e vídeos com uma abordagem clara do status quo, como os vídeos da ONU e outros de característica econômica, os entrevistados afirmam que não adotam apenas um conceito para o ensino do tema sustentabilidade no curso.

Os entrevistados apresentaram diversos pontos de vista em relação ao tipo de mudança proporcionado pela inserção do tema dentro de um curso que, em sua natureza, é de status quo. Nesse sentido, para conseguir situar o curso de Ciências Contábeis da FEA/USP, será utilizado o quadro-resumo da teoria com a identificação das características do status quo e reformista, já que não há evidências sobre uma adesão do curso de contabilidade para uma reforma radical da sociedade. A Tabela 5 apresenta as características das duas correntes e as partes grifadas correspondem à natureza do curso.

Tabela 5

Definição da natureza do conceito de sustentabilidade do curso

Corrente Status Quo

Corrente Reformista

Solução é o crescimento econômico;

Redução do poder do Estado;

Desenvolvimento tecnológico por meios de gestão

de informação.
Aceitação do problema e crítica às atuais políticas

empresariais e governamentais;

Mudanças podem ocorrer dentro das estruturas ao

longo do tempo;

Modificações de mercado e reforma do governo.

Fonte: adaptado de Hoppwood et al. (2005)

O que foi destacado dentro do quadro foi o que se percebeu nas falas dos entrevistados e na análise das disciplinas. O que se percebe é que o curso de Ciências Contábeis por si é inegavelmente um elemento do status quo, mas a tentativa de inserir discussões que ainda são marginalizadas dentro do curso e a percepção de que as práticas devem mudar, demonstram uma intenção de reforma. Nesse sentido, a Figura 2 posiciona o curso em um quadrante dividido entre EA ou EDS voltada ao status quo, reforma e transformação radical e, conjuntamente, se isso está no nível de habitualização, objetificação ou sedimentação.

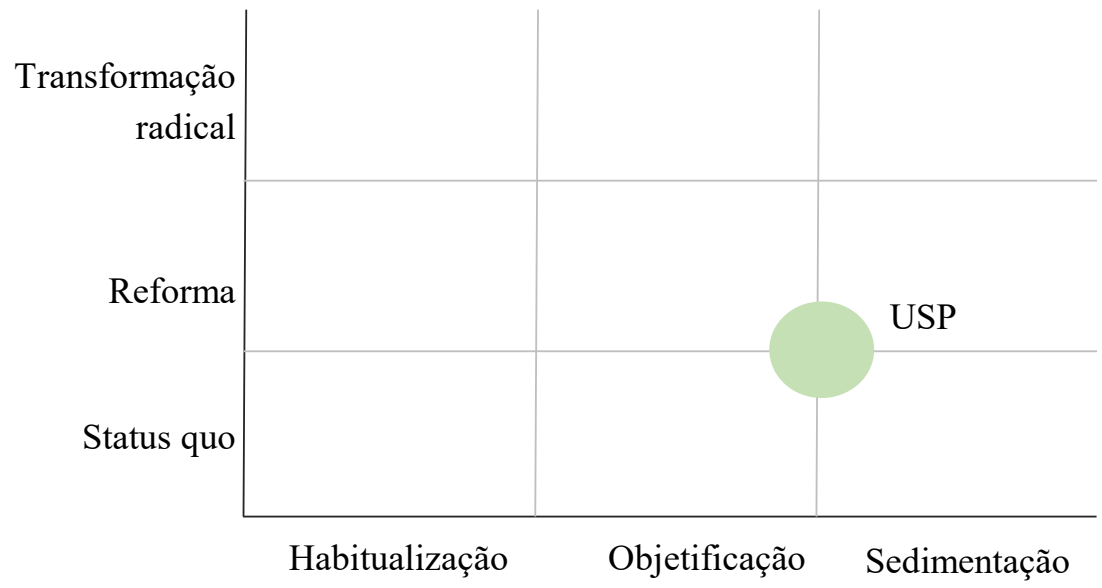

Figura 2. Mapeamento do tema sustentabilidade dentro do curso de Ciências Contábeis da FEA/USP em relação ao nível de institucionalização com a natureza de EA ou EDS oferecidos. 
Como a figura demonstra, o curso de Ciências Contábeis da FEA/USP possui um nível de institucionalização que está em migração para a sedimentação, ou institucionalização do tema sustentabilidade, enquanto sua natureza para esse ensino se enquadra dentro da manutenção do status quo para uma característica reformista. A Figura 3 apresenta a característica das disciplinas ofertadas com nível que passa do técnico ao interdisciplinar, holístico e com resultados positivos à sociedade.

\section{Curso de CC da FEA/USP}

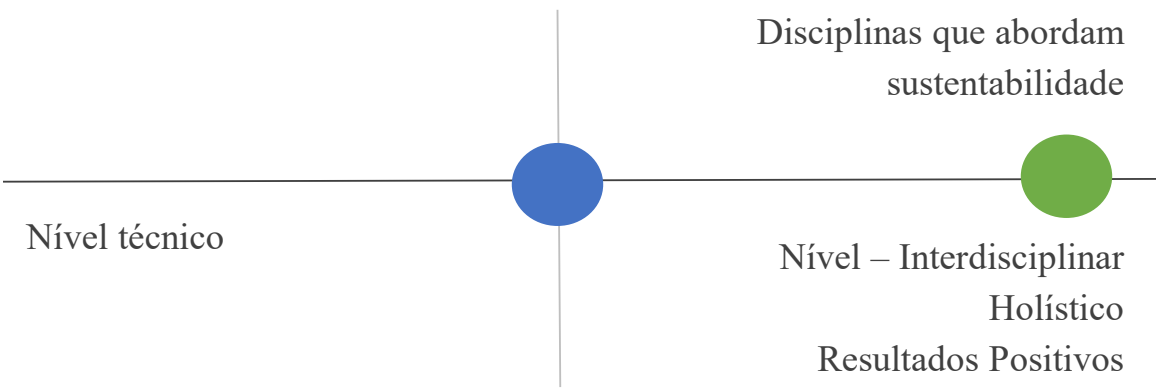

Figura 3. Nível do ensino de sustentabilidade dentro curso de Ciências Contábeis da FEA/USP.

Fonte: elaborado pelos autores.

Para a elaboração dessa figura, se fez necessária a divisão do curso como um todo e da disciplina que aborda sustentabilidade. Essa divisão se deu pelo fato de as entrevistas serem divergentes com relação ao tema e em como ele está inserido no curso. Por se tratar de disciplinas optativas, elas acabam por ter características diferentes das disciplinas obrigatórias da matriz curricular.

$\mathrm{O}$ que se percebe é que o ensino de sustentabilidade no curso tem uma tendência em ser holístico e interdisciplinar, pois isso faz parte da natureza do tema. Por outro lado, como relatado nas entrevistas, o curso em si acaba por ficar isolado dentro do departamento, com abertura apenas para as disciplinas que são obrigatórias e que fazem parte de outros centros, como, por exemplo, Direito, Estatística, Matemática etc. Nessa perspectiva, o ensino de contabilidade dentro do curso analisado está entre o nível técnico e holístico/ interdisciplinar, enquanto o ensino de sustentabilidade aborda de maneira mais interligada outras áreas do conhecimento. No entanto, ambos possuem resultados positivos, pela relevância e qualidade do curso: relevância da produção acadêmica e qualidade na formação dos alunos que são cooptados por grandes empresas.

\subsection{Discussão dos resultados}

O primeiro ponto observado foi a utilização da teoria Institucional para analisar o nível de institucionalização que o tema encontra dentro do curso estudado. Foi possível identificar o nível entre semiinstitucionalizado (objetificação) em transição para o institucionalizado (sedimentação). Isso se deve a diversos fatores, como o tempo que disciplinas que abordam o tema estão no programa, a inserção de mais de uma disciplina sobre o assunto, produção acadêmica relevante, ex-alunos trabalhando com o assunto, presença de champions (defensores da ideia), ausência de resistência por parte da instituição ou de outros docentes.

Dessa forma, foi feito um mapeamento da posição do curso de Ciências Contábeis da FEA/USP com relação ao tipo de EA ou EDS que está sendo oferecido aos alunos, se apresentando entre a manutenção do status quo e uma visão mais reformista da sociedade. Outro mapeamento foi entre o nível do conhecimento dado na instituição, que varia de conhecimento técnico até o mais holístico/interdisciplinar e com resultados positivos. De acordo com o observado durante a pesquisa, se fez necessário separar o curso em si da disciplina que aborda sustentabilidade. 
O primeiro é devido ao fato do curso de Ciências Contábeis não ter uma abordagem holística nem interdisciplinar além do exigido normalmente na legislação. Já a disciplina que aborda sustentabilidade, por sua natureza, demanda um diálogo com outras áreas do conhecimento, sendo que isso foi observado tanto no perfil de quem procura a disciplina, não se atendo somente aos estudantes de Ciências Contábeis, quanto nos palestrantes que pertencem às mais diversas profissões.

Com relação ao isomorfismo, foi identificado o tipo normativo, que tem relação com a formação de profissionais, especialização acadêmica e sucessão de cargos. Esse ponto é importante, já que o aluno que tem acesso aos conceitos de sustentabilidade, dentro da profissão contábil, possui um diferencial de conhecimento.

Essa questão estratégica também se apresenta nas empresas que, em busca de uma relação transparente com seus stakeholders, estão aderindo aos relatórios de sustentabilidade. Para tal procedimento, há o surgimento da necessidade de mão de obra qualificada para elaboração e evidenciação desses relatórios. Se em um primeiro momento grandes corporações estão aderindo ao novo modelo, como isso se aplicaria às pequenas e médias empresas?

Tem-se, assim, um problema estrutural, pois se os novos contadores geralmente irão trabalhar nesse tipo de organização, sem acesso ao conhecimento sobre sustentabilidade, como poderiam auxiliar na tomada de decisão? Outra questão que merece reflexão é o fato de que se a divulgação ambiental e social ainda é voluntária, tende-se a exteriorizar para a sociedade informações positivas sobre a organização.

São questões que merecem debates e reflexões por parte das próprias instituições de ensino: até que ponto o conhecimento oferecido nas faculdades e universidades são responsáveis pelo tipo de resultado que se tem da porta para fora? $\mathrm{Ou}$, ainda, como um contador pode influenciar diretamente seu ambiente de trabalho a partir do know-how adquirido na sua instituição de ensino?

Outro problema identificado é que para ensinar sustentabilidade deveria haver uma adesão por parte do corpo docente, para que fosse ensinada de forma holística (BRASIL, 1999). Também há a falta de identificação do tema com as áreas mais tradicionais do conhecimento contábil. De acordo com a Lei n. ${ }^{\circ}$ 9.795/1999, a sustentabilidade deve estar presente em todas as áreas do conhecimento, não se restringindo a uma disciplina, mas o que foi observado no caso analisado é que o assunto é abordado apenas por uma parte do corpo docente, e não de forma generalizada.

Nesse sentido, uma disciplina voltada para o tema sustentabilidade, de forma aprofundada e, não apenas em alguns tópicos (dentro de uma disciplina genérica), seria um grande passo dado pelas instituições de ensino. Consequentemente, dar-se-ia oportunidade ao aluno de acessar os conceitos e poder decidir por si se vai ou não os empregar em seu ambiente de trabalho.

\section{Considerações Finais}

O objetivo geral deste trabalho foi compreender o processo de institucionalização do tema sustentabilidade em uma instituição de ensino superior no curso de Ciências Contábeis. Nessa trajetória foi possível identificar diversos fatores que vão além da sedimentação do tema, envolvendo também o papel do contador no cenário social atual, as dificuldades de inserir um tema considerado ainda marginal dentro da profissão e qual o tipo de ensino de sustentabilidade proporcionado para o aluno de contabilidade.

O exemplo do curso de Ciências Contábeis da FEA/USP pode ser seguido por outras IES, o que ajudaria aumentar, em escala, o conhecimento do assunto que hoje é preocupação mundial. Portanto, este estudo contribui para a academia no âmbito da escassez de pesquisas acadêmicas sobre a temática e com coordenadores e docentes de cursos de Ciências Contábeis, pois os resultados ampliam as discussões sobre sustentabilidade e apresentam uma ementa que está em fase de institucionalização, mesmo com a incipiência da temática na área. 
Tratar de sustentabilidade é tratar de sobrevivência em todos os sentidos: do planeta, da humanidade, chegando às empresas e às oportunidades de trabalho. Dito isso, este estudo contribui para a sociedade ao evidenciar um estágio de pré-institucionalização da temática em um curso cuja instituição é uma das maiores da América Latina. Evidenciar esse estágio significa apresentar que os egressos deste curso estão capacitados para uma perspectiva sustentável nos modelos de negócios organizacionais, atendendo a uma demanda internacional.

Como limitações da pesquisa, é possível identificar que o estudo apresenta uma análise a partir dos docentes envolvidos e de documentos, não sendo possível analisar a percepção dos alunos sobre o tema. Salientase que foi enviado um questionário aos discentes, mas a baixa taxa de respondentes inviabilizou sua utilização.

Sugere-se, para próximas pesquisas, a elaboração de um modelo de processo de institucionalização e isomorfismo voltados diretamente para o ambiente acadêmico, que em sua natureza é diferente das organizações empresariais. Uma segunda sugestão é um levantamento quantitativo, em nível nacional, sobre como está o ensino de sustentabilidade, dentro dos cursos de contabilidade, para que se possa fazer um mapeamento nacional sobre o tema nas instituições de ensino em geral.

\section{Referências}

Adams, C. A. (2018). Debate: Integrated reporting and accounting for sustainable development across generations by universities. Public Money and Management, v. 38, n. 5, p. 332-334. Recuperado de https://www.tandfonline.com/doi/abs/10.1080/09540962.2018.1477580?journalCode=rpmm20. Doi: $10.1080 / 09540962.2018 .1477580$

Adams, C.; Marielle G.; Heijltjes, G.; Marjoribanks, T.; Powell, M. (2011). «The development of leaders able to respond to climate change and sustainability challenges: The role of business schools», Sustainability Accounting, Management and Policy Journal, Vol. 2 Issue: 1, pp.165-171. Doi: https://doi-org.ez79.periodicos.capes.gov.br/10.1108/20408021111162191.

Annan-Diab, F., Molinari, C. 2017. Interdisciplinarity: Practical approach to advancing education for sustainability and for the Sustainable Development Goals. The International Journal of Management Education, 15(2). Doi: https://doi.org/10.1016/j.ijme.2017.03.006.

Assumpção, M. R., Monzoni Neto, M. P., 2020. State-of-the-art practices being reported by the PRME champions group: A reference to advance education for sustainable development. The International Journal of Management Education, 18(2). Doi: https://doi.org/10.1016/j.ijme.2020.100369.

Beltrame, I. (2015). A institucionalização do tema sustentabilidade no curso de graduação em administração. 125 f. Dissertação (Mestrado em Administração) - Universidade Estadual de Londrina, Londrina.

Berger, P. L. \& Luckmann, T. (2011). A construção social da realidade: tratado de sociologia do conhecimento. 33 ed. Petrópolis: Vozes.

Carson, R. (1962). Primavera Silenciosa. São Paulo: Melhoramentos.

Chulián, M. F. (2011). Constructing new accountants: The role of sustainability education. Revista de Contabilidad, 14, pp. 241-265. Doi: https://doi.org/10.1016/S1138-4891(11)70034-6

Conselho Nacional De Educação Câmara De Educação Superior (CNE) (2004) "Resolução CNE/CES 10, de 16 de dezembro de 2004". Recuperado em 24 de maio de 2021, de http://portal.mec.gov.br/cne/ arquivos/pdf/rces10_04.pdf

Dimaggio, P. J. \& Powell, W. W. (1983). The iron cage revisited: Collective rationality and institutional isomorphism in organizational fields. American Sociological Review, 48(2), pp. 147-160. Published by: American Sociological Association. Recuperado em 24 de maio de: https://www.jstor.org/ stable/2095101. Doi: https://doi.org/10.2307/2095101 
Dimaggio, P. J. \& Powell, W. W. (2005). A gaiola de ferro revisitada: isomorfismo institucional e racionalidade coletiva nos campos organizacionais. RAE-Revista de Administração de Empresas, 45(2), pp. 74-89. Recuperado em 24 de maio de https://rae.fgv.br/rae/vol45-num2-2005/gaiolaferro-revisitada-isomorfismo-institucional-racionalidade-coletiva-nos

Faculdade De Administração, Economia E Contabilidade Da Universidade De São Paulo (FEA/USP). (2000-2016). Plano Pedagógico do Curso De Graduação Em Ciências Contábeis FEA/USP.

Figueiró, P. S., Raufflet, E. 2015. Sustainability in higher education: a systematic review with focus on management education. Journal of Cleaner Production, 106, 22-33. Doi: https://doi.org/10.1016/j. jclepro.2015.04.118

Flick, U. (2009). Uma introdução à pesquisa qualitativa. 3 Ed. Porto Alegre: Bookman.

Gonçalves-Dias, S. L. F., Herrera, C. B. \& Cruz, M. T. D. S. (2013). Desafios (e dilemas) para inserir 'Sustentabilidade' nos currículos de administração: um estudo de caso. Revista de Administração Mackenzie, 14(3), pp. 119-153. Doi: https://doi.org/10.1590/S1678-69712013000300006

Gray, R. \& Collison, D. (2002). Can't see the wood for the trees, can't see the trees for the numbers? Accounting education, sustainability and the public interest. Critical Perspectives on Accounting, 13(5-6), pp. 797-836. Doi: https://doi.org/10.1006/cpac.2002.0554

Hahn, R. \& Reimsbach, D. (2014). Are we on track with sustainability literacy? A viewpoint on the influence of sustainability and accounting education on future managers' processing of sustainability information. Journal of Global Responsibility, 5(1), pp. 55-67. Doi: 10.1108/JGR-12-2013-0016

Hopwood, B., Mellor, M. \& O’brien, G. (2005). Sustainable development: mapping different approaches. Sustainable development, 13(1), pp. 38-52. Published online in Wiley InterScience (www.interscience. wiley.com). DOI: 10.1002/sd.244 Doi: 10.1002/sd.244

Jacobi, P. (2003). Educação ambiental, cidadania e sustentabilidade. Cadernos de pesquisa, 118 (3), pp. 189-205. Recuperado em 24 de maio de 2021 de: https://repositorio.usp.br/item/001323527. Doi: $10.1590 / \mathrm{s} 0100-15742003000100008$

Jacobi, P. R., Raufflet, E. \& Arruda, M. P. (2011). Educação para a sustentabilidade nos cursos de administração: reflexão sobre paradigmas e práticas. Revista de Administração Mackenzie, 12(3), pp. 21-50. Recuperado em 24 de maio de 2021 de: http://www.spell.org.br/documentos/ver/4260/ educacao-para-a-sustentabilidade-nos-cursos-de-administracao--reflexao-sobre-paradigmas-epraticas/i/pt-br

Lei no 9.795, de 27 de abril de 1999. Dispõe sobre a educação ambiental, institui a Política Nacional de Educação Ambiental e dá outras providências. Recuperado em 24 de maio de 2021 de: http://www.planalto.gov.br/ccivil_03/leis/19795.htm\#: :text=LEI\%20No\%209.795\%2C\%20 DE\%2027\%20DE\%20ABRIL\%20DE\%201999.\&text=Disp\%C3\%B5e\%20sobre\%20a\%20 educa $\%$ C3\% A7\%C3\%A3o\%20ambiental,Ambiental\%20e\%20d\%C3\%A 1\%20outras\%20 provid\%C3\%AAncias.

Lozano, R., Lukman, R., Lozano, F. J., Huisingh, D., \& Lambrechts, W. (2013). Declarations for sustainability in higher education: becoming better leaders, through addressing the university system. Journal of Cleaner Production, 48, pp. 10-19. Recuperado em 24 de maio de 2021 de: https://www. sciencedirect.com/science/article/abs/pii/S0959652611003775. Doi: https://doi.org/10.1016/j. jclepro.2011.10.006

Meyer, J. W. \& Rowan, B. (1977). Institutionalized organizations: Formal structure as myth and ceremony. American journal of sociology, 83(2), pp. 340-363. Recuperado em 24 de maio de 2021 de: http:// www.jstor.org/stable/2778293 . 
Moraes, R. (1999). Análise de conteúdo. Revista Educação, 22 ( 37), pp. 7-32, 1999. Recuperado em 24 de maio de 2021 de: http://cliente.argo.com.br/ mgos/analise_de_conteudo_moraes.html

Organização das Nações Unidas para a Educação, a Ciência e a Cultura - UNESCO (2005). Década da Educação das Nações Unidas para um Desenvolvimento Sustentável, 2005-2014: documento final do esquema internacional de implementação: UNESCO: Brasília. Recuperado em 24 de maio de 2021 de: http://www.peaunesco-sp.com.br/ano_inter/ano_energia/decada_do_desenvolvimento_ sustentavel.pdf

Parkes, C., Buono, A. F., Howaidy, G. 2017. The Principles for Responsible Management Education (PRME): The first decade - What has been achieved? The next decade - Responsible Management Education's challenge for the Sustainable Development Goals (SDGs). The International Journal of Management Education, 15(2), pp. 61-65. Doi: https://doi.org/10.1016/j.ijme.2017.05.003

Rasche, A., Gilbert, D. U. \& Schedel, I. (2013). Cross-disciplinary ethics education in MBA programs: Rhetoric or reality? Academy of Management Learning \& Education, 12(1), pp. 71-85. Recuperado em 24 de maio de 2021 de: https://www.jstor.org/stable/23412393

Saravanamuthu, K. (2015). Instilling a sustainability ethos in accounting education through the Transformative Learning pedagogy: A case-study. Critical Perspectives on Accounting, 32, pp. 1-36. Doi: $10.1016 /$ j.cpa.2015.05.008

Silva Junior, A. da, Vasconcelos, K. C. de A., Silva, V. C. da, \& Campos, G. M. (2019). A sustentabilidade na perspectiva de discentes de graduação em Ciências Contábeis: prevalece a lógica oportunista e utilitarista. Revista Contemporânea De Contabilidade, 16(41), pp. 93-116. Doi: https://doi. org/10.5007/2175-8069.2019v16n41p93

Tolbert, P. S. \& Zucker, L. G. (1999). A institucionalização da teoria institucional. In Caldas, M. et al. (eds) Handbook de Estudos Organizacionais. São Paulo: Atlas, pp. 194-217.

Wright, T. (2004). The evolution of sustainability declarations in higher education. In Higher education and the challenge of sustainability. Springer Netherlands, pp. 7-19. Doi: 10.1007/0-306-48515-X_2

Wyness, L., Dalton, F., 2018. The value of problem-based learning in learning for sustainability: Undergraduate accounting student perspectives. Journal of Accounting Education, 45, 1-19. Doi: https://doi.org/10.1016/j.jaccedu.2018.09.001.

Yin, R. (2010). Estudo de caso: planejamento e métodos. Porto Alegre: Bookman.

Zucker, L. G. (1977). The role of institutionalization in cultural persistence. American sociological review, pp. 726-743. Doi: https://doi.org/10.2307/2094862 